\title{
Produção de biomassa e lipídios pela levedura Rhodotorula mucilaginosa utilizando a manipueira como substrato
}

\author{
Biomass and lipid production by the yeast Rhodotorula mucilaginosa using cassava \\ wastewater as the substrate
}

\begin{abstract}
Josevan da Silva ${ }^{1 *}$, Flávio Luiz Honorato da Silva1, Sharline Florentino de Melo Santos², José Evangelista Santos Ribeiro', Lorena Lucena de Medeiros' ${ }^{1}$, Andrea Lopes de Oliveira Ferreira ${ }^{2}$

1 Universidade Federal da Paraíba (UFPB), Centro de Tecnologia, Departamento de Engenharia de Alimentos, João Pessoa/PB - Brasil

2 Universidade Federal da Paraíba (UFPB), Centro de Tecnologia, Departamento de Engenharia Química, João Pessoa/PB - Brasil
\end{abstract}

\section{*Corresponding Author}

Josevan da Silva, Universidade Federal da Paraíba (UFPB), Centro de Tecnologia, Departamento de Engenharia de Alimentos, Via Expressa Padre Zé, s/n, Castelo Branco III, CEP: 58051-900, João Pessoa/PB - Brasil, e-mail: josevanufpb@gmail.com

Cite as: Biomass and lipid production by the yeast Rhodotorula mucilaginosa using cassava wastewater as the substrate. Braz. J. Food Technol., v. 21, e2017145, 2018.

Received: Sept. 07, 2017; Accepted: May 30, 2018

\section{Resumo}

Devido à elevada e intensa atividade industrial, todos os dias são gerados milhares de toneladas de resíduos agroindustriais. Um desses resíduos, a manipueira, é um líquido obtido durante o processamento da mandioca. Assim, este estudo objetivou avaliar o efeito da variação da concentração de manipueira sobre a produção de biomassa e lipídios pela levedura Rhodotorula mucilaginosa. Foram produzidos 4,1, 6,95, 5,77 g..-1 de biomassa e 13,33\%, 7,71\% e 8,47\% de lipídios nos cultivos com $50 \%, 75 \%$ e $100 \%$ de manipueira, respectivamente. No cultivo realizado em meio sintético, produziram-se 9,39 g.L-1 de biomassa e 41,92\% de lipídios. O cultivo com 100\% de manipueira apresentou o melhor coeficiente de conversão de açúcares redutores em biomassa e o cultivo em meio sintético o melhor coeficiente para lipídios. Dessa forma, a manipueira mostrou ser um bom substrato para o crescimento da levedura Rhodotorula mucilaginosa e para a produção de lipídios, sendo que essa produção ainda pode ser otimizada.

Palavras-chave: Resíduo agroindustrial; Cultivo; Lipídios microbianos, Razão C/N, Açúcares redutores, Glicose.

\section{Abstract}

Due to elevated and intense industrial activity, thousands of tons of waste are generated every day. One of these wastes, cassava wastewater, is a liquid generated during cassava processing. Thus this study aimed to evaluate the effect of varying the concentration of cassava wastewater on the production of biomass and lipids by the yeast Rhodotorula mucilaginosa. The quantities of biomass produced were $4.1,6.95$ and $5.77 \mathrm{~g} . \mathrm{L}^{-1}$ plus $13.33 \%, 7.71 \%$ and $8.47 \%$ of lipids during the cultivations with $50 \%, 75 \%$ and $100 \%$ of cassava wastewater, respectively. The synthetic cultivation produced $9.39 \mathrm{~g} . \mathrm{L}^{-1}$ of biomass and $41.92 \%$ of lipids. The culture with $100 \%$ cassava wastewater presented the best conversion efficiency coefficient of total reducing sugars to biomass and the synthetic culture, without cassava wastewater, the best coefficient for lipids. Thus cassava wastewater was shown to be a potential substrate for the growth of the yeast Rhodotorula mucilaginosa and for lipid production, and this production could be further optimized.

Keywords: Agro-industrial waste; Culture; Microbial lipids; C/N ratio; Reducing sugars; Glucose.

\section{Introdução}

A intensa e constante atividade industrial é responsável pela geração de milhões de toneladas de resíduos agroindustriais em todo o mundo (MAKRIS et al., 2007). Grande parte desses resíduos não é aproveitada, sendo descartada diretamente no meio ambiente e podendo causar danos à flora e fauna presentes, desequilibrando ecossistemas. 
Um desses resíduos origina-se durante o processamento das raízes da mandioca (Manihot esculenta Crantz) sadias, limpas e secas, já que estas são prensadas e lavadas, resultando um volume extra de um líquido amarelo claro, conhecido popularmente como manipueira (BARRETO et al., 2014; BRITO et al., 2015).

A composição nutricional da manipueira é excelente, devido à presença de minerais, como fósforo, potássio, magnésio; além de a manipueira ser boa fonte de açúcares fermentescíveis e nitrogênio, favorável ao crescimento de micro-organismos, esta pode ser também utilizada como fertilizante (DUARTE et al., 2012).

De acordo com Sawangkeaw e Ngamprasertsith (2013), leveduras são amplamente utilizadas na biotecnologia, porque são fáceis de cultivar e apresentam um bom histórico com relação à segurança de cultivo, já que poucas espécies são patogênicas. São úteis também para a produção renovável e sustentável de óleos biodegradáveis com potencial para uso em gêneros alimentícios, combustíveis e produtos químicos (SITEPU et al., 2014).

Para a produção de lipídios, devem-se escolher linhagens que apresentem uma melhor cinética de desenvolvimento, com uma maior velocidade de crescimento, necessitando de menores tempos de cultivo, que não produzam substâncias indesejáveis e que tenham a capacidade de metabolizar substratos de custo reduzido (POLl et al., 2013).

A produção de substâncias de interesse da indústria, utilizando-se resíduos agroindustriais, configura-se como uma importante alternativa para a redução dos impactos ambientais e a agregação de valor ao resíduo. Lipídios microbianos podem ser produzidos utilizando-se substratos pouco onerosos, como glicerol bruto, soro de leite, gordura bruta e óleos originários de uma pirólise (ZHAO et al., 2008).

Quando comparados aos óleos obtidos de sementes oleaginosas, os lipídios microbianos apresentam muitas vantagens, como: i) ciclo de vida mais curto; ii) requerimento de menor mão de obra; iii) não são afetados pelo local, pelo clima e pela estação; iv) possibilidade de produção em sistemas fechados, e v) ampliação de escala (THIRU et al., 2011; LIANG; JIANG, 2013).

Leveduras do gênero Rhodotorula são aeróbios estritos com características metabólicas peculiares. Uma delas é a capacidade de acumular lipídios durante a fase estacionária de crescimento (DWORECKA-KASZAK; KIZERWETTER-SWIDA, 2011). Entre as leveduras pertencentes a esse gênero, a Rhodotorula mucilaginosa tem sido utilizada pela capacidade de acúmulo de lipídios e carotenoides no interior de suas células (MOLINÉ et al., 2012; LI et al., 2010).

Dessa forma, neste trabalho, buscou-se avaliar a influência da concentração de manipueira do meio de cultivo sobre a produção de biomassa e de lipídios pela levedura $R$. mucilaginosa.

\section{Material e métodos}

\subsection{Manipueira}

A manipueira utilizada foi gentilmente cedida por uma indústria de farinha localizada no Estado da Paraíba, Brasil, e armazenada a $-18{ }^{\circ} \mathrm{C}$ logo após a coleta. Para remoção dos compostos tóxicos e possíveis inibidores, foi realizado um tratamento térmico durante 20 min, a uma temperatura de $85^{\circ} \mathrm{C}$. Logo em seguida, a manipueira foi resfriada e centrifugada a 4520 RCF por 10 min, sendo o sobrenadante coletado e utilizado como meio para os cultivos.

O teor de cianeto livre foi determinado através do conjunto Quantofix (Sigma- Aldrich - Brasil). As amostras de manipueira in natura e após o tratamento térmico foram submetidas à análise de cianeto livre.

\subsection{Micro-organismo}

Foi utilizada a levedura Rhodotorula mucilaginosa CCT 7688, fornecida pela Fundação André Tosello, coleção de culturas tropicais de São Paulo. Para o crescimento e a manutenção da levedura $R$. mucilaginosa, para facilitar o repique periódico, as colônias foram incubadas em Placas de Petri com meio YMA (Yeast Malt Agar), composto por $10 \mathrm{~g} . \mathrm{L}^{-1}$ de glicose, $3 \mathrm{~g} . \mathrm{L}^{-1}$ de extrato de levedura, $3 \mathrm{~g} . \mathrm{L}^{-1}$ de extrato de malte, $5 \mathrm{~g} . \mathrm{L}^{-1}$ de bacto peptona e $20 \mathrm{~g} . \mathrm{L}^{-1}$ de ágar.

As placas foram incubadas em estufa a $30{ }^{\circ} \mathrm{C}$ e, após três dias do inóculo, para a manutenção das colônias, as placas foram colocadas em refrigerador à temperatura de $4^{\circ} \mathrm{C}$.

\subsection{Cultivos}

Para a obtenção do pré-inóculo, adicionaram-se $5 \mathrm{~mL}$ de água destilada estéril a uma Placa de Petri contendo a levedura $R$. mucilaginosa, raspando-se as células até formar uma suspensão. $\mathrm{O}$ volume de $5 \mathrm{~mL}$ foi transferido para um frasco Erlenmeyer de $500 \mathrm{~mL}$ contendo $200 \mathrm{~mL}$ do meio utilizado para o cultivo sintético.

O Erlenmeyer foi levado para a incubadora tipo "Shaker" a $30{ }^{\circ} \mathrm{C}$ e $200 \mathrm{rpm}$. Após $24 \mathrm{~h}$, o meio foi centrifugado e o sobrenadante descartado. Foram adicionados $20 \mathrm{~mL}$ de água destilada estéril e a concentração celular foi determinada em câmara de Neubauer, para cálculo do volume de inóculo correspondente a $1 \times 10^{7}$ células. $\mathrm{mL}^{-1}$.

Foram realizados quatro cultivos, sendo três deles utilizando-se o meio à base de manipueira (50\%, 75\% e $100 \%$ ) e um experimento controle (cultivo em meio sintético). Os meios à base de manipueira foram suplementados com $3 \mathrm{~g} . \mathrm{L}^{-1}$ de extrato de levedura, não se utilizou glicose nem 
minerais, obtendo-se uma razão $\mathrm{C} / \mathrm{N}$ de 8,0 para todos os meios com o resíduo.

O cultivo realizado em meio sintético (EC) era composto de $40 \mathrm{~g} \cdot \mathrm{L}^{-1}$ de glicose, $8,0 \mathrm{~g} \cdot \mathrm{L}^{-1}$ de $\mathrm{KH}_{2} \mathrm{PO}_{4}, 0,5 \mathrm{~g} \cdot \mathrm{L}^{-1}$ de $\mathrm{MgSO}_{4} \cdot 7 \mathrm{H}_{2} \mathrm{O}$ e 3,0 g.L.-1 de extrato de levedura (FRENGOVA et al., 1994) e uma razão C/N de 53,0. Todos os cultivos foram realizados em triplicata.

Os meios foram preparados e autoclavados a $1 \mathrm{~atm}$ por $15 \mathrm{~min}$. Aos meios estéreis, foram adicionados volumes iguais de pré-inóculo correspondentes a $1 \times 10^{7}$ células. $\mathrm{mL}^{-1}$. O cultivo foi mantido em incubadora tipo "Shaker" (Logen - LS4900 - THZ), a $30{ }^{\circ} \mathrm{C}$ e 200 rpm por $120 \mathrm{~h}$.

\subsection{Métodos analíticos}

\subsubsection{Biomassa}

Alíquotas de $2 \mathrm{~mL}$ foram retiradas durante os intervalos de tempo de 0, 24, 48, 72, 96 e 120 h para análise de concentração de biomassa ( $\left.g \cdot \mathrm{L}^{-1}\right)$. Os volumes coletados foram utilizados para leitura em espectrofotômetro (Bioespectro SP 220) no comprimento de onda de $600 \mathrm{~nm}$. O valor da absorbância foi convertido em concentração através de uma curva padrão de biomassa. Ao final do cultivo (120 h), os lipídios foram extraídos e quantificados. Em nenhuma etapa, a biomassa foi lavada com água destilada.

\subsubsection{Consumo do substrato}

Para monitoramento do processo de consumo de açúcares pela levedura, durante os intervalos de tempo de 0, 24, 48, 72, 96 e $120 \mathrm{~h}$, foram coletados $2 \mathrm{~mL}$ do meio, sendo centrifugados (mini spin Eppendorf) a 7.300 RCF por 10 min, sendo o sobrenadante utilizado para análise de açúcares redutores pelo método de DNS (MILLER, 1959).

\subsubsection{Lipídios totais}

Para quantificação dos lipídios totais, foram utilizadas as biomassas produzidas ao final do cultivo (120 h). $O$ restante do fermentado (cerca de $180 \mathrm{~mL}$ ) foi coletado e centrifugado a 2.712 RCF por $10 \mathrm{~min}$. O sobrenadante foi descartado e a biomassa foi seca, sem ser submetida à lavagem prévia com água, em estufa a $105^{\circ} \mathrm{C}$ por $24 \mathrm{~h}$. A biomassa seca foi macerada com grau e pistilo para diminuição das partículas e para facilitar a ação dos solventes durante a extração.

Primeiramente, a biomassa seca foi tratada com uma solução de $\mathrm{HCl} 2$ mol. L-1 para rompimento da parede celular. O teor de lipídios foi determinado através do método de Bligh e Dyer (1959) adaptado por Manirakiza et al. (2001), através da extração dos lipídios polares e não polares da biomassa, utilizando-se uma mistura de metanol e clorofórmio. Formaram-se três fases: a fase superior foi descartada, a inferior foi evaporada em estufa a $70^{\circ} \mathrm{C}$ e os lipídios, quantificados por gravimetria em massa seca.

\subsubsection{Fatores de conversão de substrato em biomassa e lipídios}

Foram determinados os fatores de conversão de substrato em biomassa $\left(Y_{x / s}\right)$ e em produto $\left(Y_{p / s}\right)$, de acordo com as equações 1 e 2 :

$$
\begin{aligned}
& Y x / s=\frac{X-X_{0}}{S o-S} \\
& Y p / s=\frac{P-P_{0}}{S o-S}
\end{aligned}
$$

Em que:

$X=$ biomassa final; $X_{0}=$ biomassa inicial; $S_{0}=$ substrato inicial; $S=$ substrato final; $P=$ produto final; $P_{0}=$ produto inicial.

\subsubsection{Análise estatística}

Os experimentos foram tratados por meio da Análise de Variância (ANOVA) e as médias foram comparadas pelo Teste de Tukey, no nível de significância de 5\%.

\section{Resultados e discussão}

\subsection{Biomassa}

Na Figura 1, apresenta-se o resultado para a biomassa produzida pela Rhodotorula mucilaginosa ao longo do tempo de cultivo.

De acordo com a Figura 1, o experimento com $75 \%$ de manipueira apresentou a mais elevada produção de biomassa entre os três experimentos realizados em meio à base de manipueira; entretanto, sua biomassa final foi inferior apenas quando comparada à do cultivo realizado em meio sintético. A menor biomassa foi obtida quando se utilizou $50 \%$ de manipueira e isso pode ser justificado em função da menor concentração de fonte de carbono no meio.

Os experimentos com 50\%, 75\% e 100\% apresentaram taxas de crescimento muito similares nas 24 primeiras horas

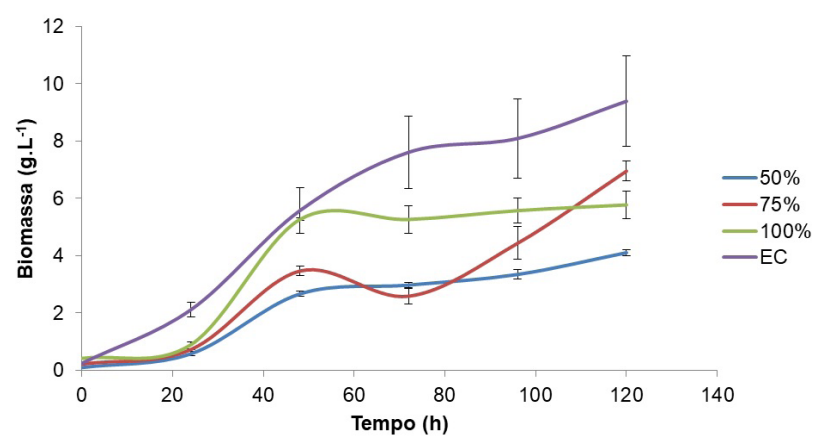

Figura 1. Biomassa produzida pela levedura Rhodotorula mucilaginosa ao longo do tempo de cultivo. 
de cultivo e todos atingiram suas respectivas biomassas máximas em $120 \mathrm{~h}$ após a inoculação. O teor de cianeto livre presente na manipueira, inicialmente de 3,0 mg. $\mathrm{L}^{-1}$, foi reduzido para $1,0 \mathrm{mg} . \mathrm{L}^{-1}$ após o tratamento térmico.

Li et al. (2010) verificaram que a fonte de carbono não influenciou significativamente no crescimento da levedura R. mucilaginosa. Foram utilizados glicose, sacarose, xilose e o hidrolisado da fécula de mandioca como fontes de carbono para crescimento da levedura, produzindo-se, respectivamente, 13, 13, 12 e 11 g.L $\mathrm{L}^{-1}$ de biomassa. Entretanto, no mesmo estudo, foram utilizados extrato de levedura, peptona, $\mathrm{NaNO}_{3},\left(\mathrm{NH}_{4}\right)_{2} \mathrm{SO}_{4}$ e $\left(\mathrm{NH}_{4}\right)_{2} \mathrm{NO}_{3}$ como fontes de nitrogênio; os referidos autores observaram que, com o uso de $\left(\mathrm{NH}_{4}\right)_{2} \mathrm{SO}_{4}$ e peptona, foram obtidas as maiores biomassas, 23 e $24 \mathrm{~g} . \mathrm{L}^{-1}$, respectivamente.

As biomassas produzidas no presente estudo são semelhantes às encontradas por Reyna-Martínez et al. (2015), que produziram $6,27 \mathrm{~g} . \mathrm{L}^{-1}$ quando cultivaram a levedura R. mucilaginosa em um meio sintético à base de glicose, extrato de levedura e peptona, e aos resultados de Cheng e Yang (2016), que obtiveram 6 g.L.-1 de biomassa usando uma mistura de resíduos e melaço de cana, suplementados com extrato de levedura, como substrato.

No estudo de Wang et al. (2012), um aumento na concentração do hidrolisado do amido de mandioca provocou uma elevação da biomassa produzida pela levedura oleaginosa Rhodosporidium toruloides. A máxima biomassa, equivalente a $15 \mathrm{~g} . \mathrm{L}^{-1}$, foi alcançada quando a concentração do hidrolisado foi de $80 \%$.

\subsection{Lipídios}

Os resultados para a produção de lipídios pela levedura $R$. mucilaginosa em manipueira encontram-se na Tabela 1.

De acordo com a Tabela 1, a concentração de manipueira no meio de cultivo influenciou na produção lipídica, já que houve diferença significativa $(p<0,05)$ entre os experimentos com 50\% de manipueira, $75 \%$ e controle. Pôde-se constatar uma redução na produção lipídica quando se elevou a concentração de manipueira.

A presença de nutrientes, como o sulfato de magnésio e o fosfato de potássio, no cultivo em meio sintético, pode ter contribuído para a elevada produção lipídica, comparada aos outros experimentos. Íons, como
$\mathrm{MnSO}_{4}, \mathrm{CaCl}_{2}, \mathrm{ZnSO}_{4} \cdot 7 \mathrm{H}_{2} \mathrm{O}$ e $\mathrm{FeCl}_{3} \cdot 6 \mathrm{H}_{2} \mathrm{O}$, exerceram efeitos positivos sobre a produção de lipídios e o crescimento celular de Rhodosporidium toruloides (WANG et al., 2012).

No cultivo com o meio sintético, conseguiu-se a maior produção lipídica e, quanto aos cultivos em meio à base de manipueira, no experimento realizado utilizando-se $50 \%$ do resíduo, conseguiu-se o mais elevado teor de lipídios. Não houve diferença significativa $(p<0,05)$ entre a produção lipídica usando-se 75\% e 100\% de manipueira.

No cultivo controle, a alta razão C/N (53) pode ter interferido no crescimento celular, em virtude do excesso de carbono no meio, e favorecido o acúmulo de lipídios. Nos cultivos com a manipueira, pode ter ocorrido o inverso, devido ao fato de a razão $\mathrm{C} / \mathrm{N}$ ser bem inferior $(8,0)$.

Wang et al. (2012) verificaram que um aumento na concentração do hidrolisado do amido de mandioca ocasionou uma elevação do acúmulo de óleo pela levedura $R$. toruloides. Quando foi utilizado um meio contendo $35 \%$ do hidrolisado, a produção lipídica foi equivalente a $15 \%$ (massa/massa), produção esta semelhante à obtida quando se utilizou $50 \%$ de manipueira no presente estudo $(13,33 \%)$.

A diferença no acúmulo de lipídios entre o cultivo controle e os meios à base de manipueira pode ser justificada pela diferença entre as razões $\mathrm{C} / \mathrm{N}$ dos meios (53,0 versus 8,0), uma vez que a transição do crescimento para o acúmulo de lipídios normalmente ocorre quando o excesso de carbono no meio está associado a uma limitação de nutrientes, geralmente o nitrogênio. De acordo com Braunwald et al. (2013), a razão C/N do meio é um dos mais importantes parâmetros para o acúmulo de óleos em leveduras, sendo que razões elevadas favorecem o acúmulo.

\subsection{Consumo do substrato}

O resultado para o consumo da fonte de carbono durante o cultivo encontra-se na Figura 2.

$\mathrm{Na}$ Tabela 2, apontam-se os coeficientes de conversão da fonte de carbono em biomassa e lipídios.

Nos experimentos utilizando-se 50\% e 100\% de manipueira, ocorreram as menores taxas de consumo de açúcar (apenas cerca de $10 \mathrm{~g} . \mathrm{L}^{-1}$ foram consumidos). O cultivo em meio sintético apresentou a maior taxa de

Tabela 1. Produção de lipídios e rendimento em relação ao substrato por $R$. mucilaginosa em manipueira em diferentes concentrações.

\begin{tabular}{ccc}
\hline Experimento & Lipídios $\mathbf{( g . 1 0 0 ~ \mathbf { g } ^ { - 1 } )}$ & Biomassa final $\left(\mathbf{g} \cdot \mathbf{L}^{-1}\right)$ \\
\hline $50 \%$ & $13,33^{\mathrm{b}} \pm 1,01$ & $4,1^{\mathrm{c}} \pm 0,10$ \\
$75 \%$ & $7,71^{\mathrm{c}} \pm 0,81$ & $6,95^{\mathrm{b}} \pm 0,34$ \\
$100 \%$ & $8,47^{\mathrm{c}} \pm 1,56$ & $5,77^{\mathrm{bc}} \pm 0,47$ \\
Controle & $41,92^{\mathrm{a}} \pm 2,13$ & $9,39^{\mathrm{a}} \pm 1,57$ \\
\hline
\end{tabular}

Letras superescritas iguais não diferem no nível de $5 \%$ de significância $p<0,05$ (Teste de Tukey). 
Produção de biomassa e lipídios pela levedura Rhodotorula mucilaginosa utilizando a manipueira como substrato Silva, J. et al.

Tabela 2. Coeficientes de rendimento da conversão de açúcares redutores totais em biomassa e lipídios.

\begin{tabular}{|c|c|c|}
\hline Experimento & $\mathrm{Y}_{\mathrm{X} / \mathrm{S}}^{*}\left(\mathbf{g} \cdot \mathbf{g}^{-1}\right)$ & $\mathbf{Y}^{*}{ }_{\mathrm{P} / \mathrm{S}}\left(\mathbf{g} \cdot \mathbf{g}^{-1}\right)$ \\
\hline $50 \%$ & $0,4825^{b} \pm 0,039$ & $0,0637^{b} \pm 0,005$ \\
\hline $75 \%$ & $0,3064^{a} \pm 0,032$ & $0,0241^{d} \pm 0,003$ \\
\hline $100 \%$ & $0,5193^{b} \pm 0,013$ & $0,0460^{c} \pm 0,008$ \\
\hline Controle & $0,2592^{a} \pm 0,032$ & $0,1104^{a} \pm 0,006$ \\
\hline
\end{tabular}

$Y_{Y}=$ Coeficiente de rendimento da conversão de açúcares redutores totais em biomassa. $Y_{\text {ofic }}$ Coeficiente de rendimento da conversão de açúcares ređutores totais em lipídios. ${ }^{*}$ Os coeficientes foram calculados com base no consumo de substrato e na biomassa e nos lipídios produzidos 120 h após o inóculo (biomassa e lipídios, ambos expressos em grama; para lipídios, calculou-se a quantidade presente na respectiva biomassa obtida, com base no percentual de lipídios obtido).

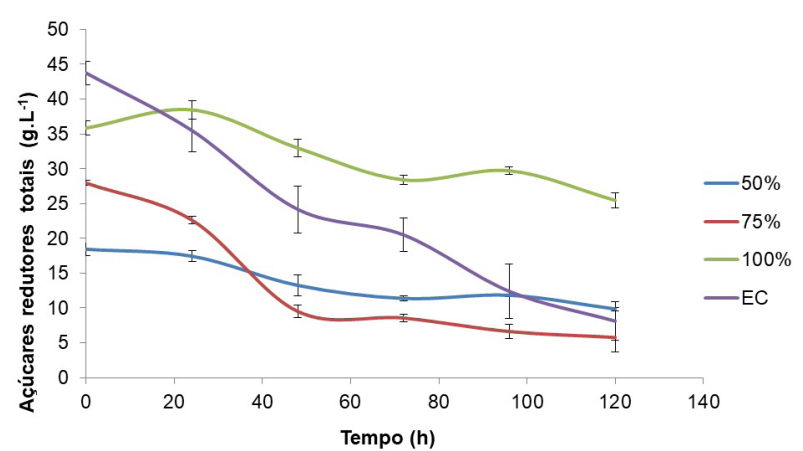

Figura 2. Consumo de açúcares redutores $\left(g \cdot \mathrm{L}^{-1}\right)$ durante o cultivo de R. mucilaginosa em manipueira com diferentes concentrações.

consumo, seguido pelo cultivo com o meio composto de $75 \%$ de manipueira.

O maior uso da fonte de carbono foi responsável pela maior biomassa produzida, assim como a menor taxa de consumo de açúcar originou a menor biomassa produzida. No experimento com $75 \%$ de manipueira, atingiu-se a menor concentração de açúcares (5,77 g.L-1 $)$, 120 h após o início do cultivo.

De acordo com Meng et al. (2009), durante a fermentação, quando ocorre excesso de carbono, na forma de glicose, em relação a algum nutriente, geralmente sobre o teor de nitrogênio, inicia-se o acúmulo de lipídios nos micro-organismos, a multiplicação celular é impedida, o carbono em excesso é convertido em lipídios e estes são armazenados intracelularmente.

Com relação ao consumo do substrato, o experimento com $100 \%$ de manipueira apresentou o melhor coeficiente de rendimento de conversão de açúcares redutores totais em biomassa $\left(0,5193 \mathrm{~g} \cdot \mathrm{g}^{-1}\right)$. Já para a produção lipídica, no experimento com controle, conseguiu-se o mais eficiente rendimento $\left(0,1104 \mathrm{~g} \cdot \mathrm{g}^{-1}\right)$.

Nos cultivos à base de manipueira, obtiveram-se os maiores coeficientes de conversão de açúcares em biomassa $\left(\mathrm{Y}_{\mathrm{x} / \mathrm{S}}\right)$, comparados com os coeficientes do cultivo em meio sintético. Na condição em que se utilizou $50 \%$ de manipueira, também foi obtido o mais elevado coeficiente de conversão da fonte de carbono em lipídios $\left(0,0637 \mathrm{~g} \cdot \mathrm{g}^{-1}\right)$, comparando-se os experimentos que utilizaram o resíduo manipueira como meio.

\section{Conclusões}

A utilização de um meio de cultivo composto de $50 \%$ de manipueira proporcionou a mais elevada produção lipídica e o melhor coeficiente de conversão da fonte de carbono em lipídios, entre as três concentrações de substrato estudadas.

Em todas as concentrações estudadas, a conversão de uma fonte de carbono originária da manipueira em biomassa mostrou-se mais eficiente do que a oriunda de uma fonte tradicional (sintética); entretanto, em relação à conversão de substrato em produto (lipídeos), a fonte controle (sintética) foi mais eficiente devido à sua elevada razão $\mathrm{C} / \mathrm{N}$.

A manipueira configura-se como um substrato potencial para o cultivo da levedura Rhodotorula mucilaginosa (biomassa), bem como para a produção de lipídios, e essa produção ainda pode ser maximizada pelo estudo da razão $\mathrm{C} / \mathrm{N}$ no meio que otimize o processo.

\section{Agradecimentos}

Os autores agradecem ao Conselho Nacional de Tecnologia e Desenvolvimento Científico (CNPq) pelo suporte financeiro, e à Fundação André Tosello pela doação do micro-organismo.

\section{Referências}

BARRETO, M. T. L.; MAGALHÃES, A. G.; ROLIM, M. M.; PEDROSA, E. M. R.; DUARTE, A. S.; TAVARES, U. E. Desenvolvimento e acúmulo de macronutrientes em plantas de milho biofertilizadas com manipueira. Revista Brasileira de Engenharia Agrícola e Ambiental, v. 18, n. 5, p. 487-494, 2014. http://dx.doi.org/10.1590/ S1415-43662014000500004.

BLIGH, E. G.; DYER, J. W. A rapid method of total lipid extraction and purification. Canadian Journal of Biochemistry and Physiology, v. 37, n. 8, p. 911-917, 1959. http://dx.doi.org/10.1139/ 059-099. PMid:13671378.

BRAUNWALD, T.; SCHWEMMLEIN, L.; GRAEFF-HÖNNINGER, S.; FRENCH, W. T.; HERNANDEZ, R.; HOLMES, W. E.; CLAUPEIN, W. Effect of different $\mathrm{C} / \mathrm{N}$ ratios on carotenoid and lipid production by Rhodotorula g/utinis. Applied Microbiology and Biotechnology, 
Produção de biomassa e lipídios pela levedura Rhodotorula mucilaginosa utilizando a manipueira como substrato Silva, J. et al.

v. 97 , n. 14 , p. $6581-6588,2013$. http://dx.doi.org/10.1007/ s00253-013-5005-8. PMid:23728238.

BRITO, V. H. S.; SILVA, E. C.; CEREDA, M. P. Digestibilidade do amido in vitro e valor calórico dos grupos de farinhas de mandioca brasileiras. Brazilian Journal of Food Technology, v. 18, n. 3 , p. 185-191, 2015. http://dx.doi.org/10.1590/1981-6723.2714.

CHENG, Y. T.; YANG, C. F. Using strain Rhodotorula mucilaginosa to produce carotenoids using food wastes. Journal of the Taiwan Institute of Chemical Engineers, v. 20, n. 1, p. 1-6, 2016.

DUARTE, A.; SILVA, Ê. F. F.; ROLIM, M. M.; FERREIRA, R. F. A. L.; MALHEIROS, S. M. M.; ALBUQUERQUE, F. S. Uso de diferentes doses de manipueira na cultura da alface em substituição à adubação mineral. Revista Brasileira de Engenharia Agrícola e Ambiental, v. 16, n. 3, p. 262-267, 2012. http://dx.doi.org/10.1590/ S1415-43662012000300005.

DWORECKA-KASZAK, B.; KIZERWETTER-SWIDA, M. Pseudomycelium forming Rhodotorula-unusual picture of biofilm. Mikologua Lekarska, v. 18, n. 2, p. 74-78, 2011.

FRENGOVA, G.; SIMOVA, E.; PAVLOVA, K.; BESHKOVA, B.; GRIGOROVA, D. Formation of carotenoids by Rhodotorula glutinis in whey ultrafiltrate. Biotechnology and Bioengineering, v. 44, n. 8, p. 888-894, 1994. http://dx.doi.org/10.1002/bit.260440804. PMid:18618906

LI, M.; LIU, G. L.; CHI, Z.; CHI, Z. M. Single cell oil production from hydrolysate of cassava starch by marine-derived yeast Rhodotorula mucilaginosa TJY15a. Biomass and Bioenergy, v. 34, n. 1, p. 101-107, 2010. http://dx.doi.org/10.1016/j. biombioe.2009.10.005

LIANG, M. H.; JIANG, J. G. Advancing oleaginous microorganisms to produce lipid via metabolic engineering technology. Progress in Lipid Research, v. 52, n. 4, p. 395-408, 2013. http://dx.doi. org/10.1016/j.plipres.2013.05.002. PMid:23685199.

MAKRIS, D. P.; BOSKOU, G.; ANDRIKOPOULOS, N. K. Polyphenolic content and in vitro antioxidant characteristics of wine industry and other agri-food solid waste extracts. Journal of Food Composition and Analysis, v. 20, n. 2, p. 125-132, 2007. http://dx.doi.org/10.1016/j.jfca.2006.04.010.

MANIRAKIZA, P.; COVACI, A.; SCHEPENS, P. Comparative study on total lipid determination using Soxhlet, Roese-Gottlieb, Bligh \& Dyer, and modified Bligh \& Dyer extraction methods. Journal of Food Composition and Analysis, v. 14, n. 1, p. 93-100, 2001. http://dx.doi.org/10.1006/jfca.2000.0972.

MENG, X.; YANG, J.; XU, X.; ZHANG, L.; NIE, Q.; XIAN, M. Biodiesel production from oleaginous microorganisms. Renewable
Energy, v. 34, n. 1, p. 1-5, 2009. http://dx.doi.org/10.1016/j. renene.2008.04.014

MILLER, G. L. Use of dinitrosalicylic acid reagent for determination of reducing sugar. Analytical Chemistry, v. 31, n. 3, p. 426-428, 1959. http://dx.doi.org/10.1021/ac60147a030.

MOLINÉ, M.; LIBKIND, D.; VAN BROOCK, M. Production of torularhodin, torulene, and -carotene by Rhodotorula yeasts. Methods in Molecular Biology (Clifton, N.J.), v. 898, n. 1, p. 275-283, 2012. http://dx.doi.org/10.1007/978-1-61779-918-1_19. PMid:22711133.

POLI, J. S.; DALLÉ, P.; SENTER, L.; MENDES, S.; RAMIREZ, M.; VAINSTEIN, M.; VALENTE, P. Fatty acid methyl ester produced by oleaginous yeast Yarrowia lipolytica QU21: an alternative for vegetable oils. Revista Brasileira de Biociências, v. 11, n. 2, p. 203-208, 2013.

REYNA-MARTÍNEZ, R.; GOMEZ-FLORES, R.; LÓPEZ-CHUKEN, U. J.; GONZÁLEZ-GONZÁLEZ, R.; FERNÁNDEZ-DELGADILLO, S.; BALDERAS-RENTERÍA, I. Lipid Production by Pure and Mixed Cultures of Chlorella pyrenoidosa and Rhodotorula mucilaginosa Isolated in Nuevo Leon, Mexico. Applied Biochemistry and Biotechnology, v. 175, n. 1, p. 354-359, 2015. http://dx.doi. org/10.1007/s12010-014-1275-6. PMid:25274117.

SAWANGKEAW, R.; NGAMPRASERTSITH, S. A review of lipid-based biomasses as feedstocks for biofuels production. Renewable \& Sustainable Energy Reviews, v. 25, n. 1, p. 97-108, 2013. http://dx.doi.org/10.1016/j.rser.2013.04.007.

SITEPU, I. R.; GARAY, L. A.; SESTRIC, R.; LEVIN, D.; BLOCK, D. E.; GERMAN, J. B.; BOUNDY-MILLS, K. L. Oleaginous yeasts for biodiesel: current and future trends in biology and production. Biotechnology Advances, v. 32, n. 7, p. 1336-1360, 2014. http:// dx.doi.org/10.1016/j.biotechadv.2014.08.003. PMid:25172033.

THIRU, M.; SANKH, S.; RANGASWAMY, V. Process for biodiesel production from Cryptococcus curvatus. Bioresource Technology, v. 102, n. 22, p. 10436-10440, 2011. http://dx.doi.org/10.1016/j. biortech.2011.08.102. PMid:21930373.

WANG, Q.; GUO, F.; RONG, Y.; CHI, Z. Lipid production from hydrolysate of cassava starch by Rhodosporidium toruloides 21167 for biodiesel making. Renewable Energy, v. 46, n. 1, p. 164-168, 2012. http://dx.doi.org/10.1016/j.renene.2012.03.002.

ZHAO, X.; KONG, X.; HUA, Y.; FENG, B.; ZHAO, Z. K. Medium optimization for lipid production through co-fermentation of glucose and xylose by the oleaginous yeast Lipomyces starkey. European Journal of Lipid Science and Technology, v. 110, n. 5, p. 405-412, 2008. http://dx.doi.org/10.1002/ejlt.200700224. 